\title{
Characterization of KIF11 as a novel prognostic biomarker and therapeutic target for oral cancer
}

\author{
KAYO DAIGO $^{1,2,5}$, ATSUSHI TAKANO ${ }^{1,3}$, PHUNG MANH THANG ${ }^{1,3}$, YOSHIHIRO YOSHITAKE ${ }^{4}$, \\ MASANORI SHINOHARA ${ }^{4}$, IWAU TOHNAI ${ }^{6}$, YOSHINORI MURAKAMI ${ }^{5}$, \\ JIRO MAEGAWA ${ }^{2}$ and YATARO DAIGO ${ }^{1,3}$ \\ ${ }^{1}$ Center for Antibody and Vaccine Therapy, Research Hospital, Institute of Medical Science Hospital, \\ The University of Tokyo, Tokyo; ${ }^{2}$ Department of Plastic and Reconstructive Surgery, \\ Yokohama City University, Yokohama; ${ }^{3}$ Department of Medical Oncology and Cancer Center, \\ Shiga University of Medical Science, Otsu; ${ }^{4}$ Department of Oral and Maxillofacial Surgery, \\ Kumamoto University, Kumamoto; ${ }^{5}$ Division of Molecular Pathology, Institute of Medical Science, \\ The University of Tokyo, Tokyo; ${ }^{6}$ Department of Oral and Maxillofacial Surgery, \\ Yokohama City University, Yokohama, Japan
}

Received August 10, 2017; Accepted October 21, 2017

DOI: $10.3892 /$ ijo.2017.4181

\begin{abstract}
Oral cancer has a high mortality rate, and its incidence is increasing gradually worldwide. As the effectiveness of standard treatments is still limited, the development of new therapeutic strategies is eagerly awaited. Kinesin family member 11 (KIF11) is a motor protein required for establishing a bipolar spindle in cell division. The role of KIF11 in oral cancer is unclear. Therefore, the present study aimed to assess the role of KIF11 in oral cancer and evaluate its role as a prognostic biomarker and therapeutic target for treating oral cancer. Immunohistochemical analysis demonstrated that KIF11 was expressed in 64 of $99(64.6 \%)$ oral cancer tissues but not in healthy oral epithelia. Strong KIF11 expression was significantly associated with poor prognosis among oral cancer patients $(\mathrm{P}=0.034)$, and multivariate analysis confirmed its independent prognostic value. In addition, inhibition of KIF11 expression by transfection of siRNAs into oral cancer cells or treatment of cells with a KIF11 inhibitor significantly suppressed cell proliferation, probably through G2/M arrest and subsequent induction of apoptosis. These results suggest that KIF11 could be a potential prognostic biomarker and therapeutic target for oral cancer.
\end{abstract}

\section{Introduction}

Oral cancer occurs at various parts of the oral cavity, such as the tongue, gingiva, and buccal mucosa, and it represents

Correspondence to: Dr Yataro Daigo, Center for Antibody and Vaccine Therapy, Research Hospital, Institute of Medical Science Hospital, The University of Tokyo, Tokyo, Japan

E-mail: ydaigo@ims.u-tokyo.ac.jp; ydaigo@belle.shiga-med.ac.jp

Key words: KIF11, prognostic biomarker, therapeutic target, oral cancer, oncoprotein the sixth most common malignant neoplasm worldwide (1). Annually, 28,030 new cases and 5,850 deaths have been estimated in the United States (1). Oral squamous cell carcinoma represents $\sim 90 \%$ of oral cancer cases. As disease progression depends on differences in oral regions, which vary in structure and function, the choice of treatment depends on the anatomical primary region of cancer. The current standard therapy is surgery followed by radiotherapy for early and localized advanced oral cancer. The survival rate has been reported to be up to $80 \%$ in the early stage and only $20-30 \%$ in the late stage (2). Deficiency in oral function is unavoidable after surgery for oral cancer, even with reconstructive surgery, such as tissue transplantation (3). After surgery and radiotherapy, local and regional recurrences have been reported in up to $90 \%$ of oral cancer patients, and additional adjuvant chemotherapy has been shown to improve survival (4-6). Despite recent advances in imaging, surgery, radiation, and systemic therapies, overall survival has improved by $15 \%$ in the last 50 years and only $5 \%$ in the last 20 years (7). Therefore, further development of non-surgical therapies, such as those targeting cancer-specific molecules, with no or low risks of adverse effects are important for oral cancer treatment.

To identify potential molecular targets for the diagnosis and treatment of cancer, we performed genome-wide gene expression analysis and subsequent tissue microarray analysis of solid tumor tissues and various normal tissues and isolated several oncoantigens involved in the development and/or progression of various solid cancers (8-30). Since members of the kinesin superfamily such as mitotic kinesins are involved in key functions during intracellular transport and cell division of cancers, we further focused on the genes encoding kinesin proteins that are upregulated in the majority of oral cancers, but scarcely expressed in normal organs. During this process, we identified kinesin family member 11 (KIF11) as a candidate target molecule. KIF11 encodes a motor protein that belongs to the kinesin-like protein family. Members of this 
protein family are known to be involved in various kinds of spindle dynamics. The function of this gene product includes chromosome positioning, centrosome separation, and bipolar spindle establishment during cell mitosis (31-33). Additionally, KIF11 plays a role in the transport of secretory proteins from the Golgi complex to the cell surface in non-mitotic cells (34). Some reports stated that KIF11 was expressed in some human cancers, including lung cancer, glioblastoma, malignant mesothelioma, and gastric cancer (35-38); however, no report revealed details of the oncogenic function and prognostic value of this protein as a therapeutic and diagnostic target for oral cancer. Therefore, the present study aimed to assess the role of KIF11 in oral cancer and evaluate its role as a prognostic biomarker and therapeutic target for treating oral cancer.

\section{Materials and methods}

Cell lines and tissue samples. Five oral cancer cell lines (FaDu, SCC9, CAL27, HSC3 and HSC4) and human keratinocytes isolated from normal oral mucosa (HOMK100) were used in this study. FaDu, SCC9, and CAL27 were purchased from American Type Culture Collection (ATCC, Rockville, MD, USA). HSC 3 and HSC4 were provided by RIKEN BioResource Center (Tsukuba, Japan), and HOMK100 was purchased from Cell Research Corporation (Singapore) (Table I). The five oral cancer cell lines were grown in monolayers in appropriate medium supplemented with $10 \%$ fetal bovine serum (FBS) and antibiotics (Thermo Fisher Scientific, Waltham, MA, USA) and were maintained at $37^{\circ} \mathrm{C}$ in an atmosphere of humidified air. HOMK cells were grown in medium supplemented with EpiLife defined growth supplement (Gibco, Grand Island, NY, USA). Eight oral squamous cell cancer tissue samples were obtained from ProteoGenex (Inglewood, CA, USA), and a normal tongue tissue was obtained from Clontech (Palo Alto, CA, USA). The population of the cancer cells in oral cancer tissues used in this study ranged from 60 to $100 \%$ (mean 82\%). In addition, we obtained 99 oral cancer and adjacent normal oral tissue samples from oral cancer patients who had undergone curative surgery at Kumamoto University for immunostaining on tissue microarrays. Individual institutional ethics committees approved this study and the use of all clinical materials.

Quantitative real-time PCR. Total RNA was extracted from cultured cells and clinical tissues using the Maxwell 16 LEV simply RNA purification kit (Promega, Madison, WI, USA) according to the manufacture's protocol. The RNA from cultured cells and clinical tissues was reverse transcribed to cDNA using Prime Script RT Master Mix (Takara Bio, Otsu, Shiga, Japan). Real-time PCR experiments were carried out with TaqMan Universal Master Mix II (Thermo Fisher Scientific). Each experiment was performed in triplicate. ACTB (Hs01060665_g1) as an internal control and KIF11 (Hs00189698_m1) primer were used (Applied Biosytems, Warrington, UK). The reaction conditions were as follows: initial denaturation for $2 \mathrm{~min}$ at $50^{\circ} \mathrm{C}$ and $10 \mathrm{~min}$ at $95^{\circ} \mathrm{C}$ followed by 40 cycles of denaturation $\left(15 \mathrm{sec}\right.$ at $95^{\circ} \mathrm{C}$ and $60 \mathrm{sec}$ at $60^{\circ} \mathrm{C}$ ). Each PCR product was run in triplicate. The relative KIF11 mRNA expression was calculated by $2^{-\Delta \Delta C \mathrm{t}}$.
Western blot analysis. Cells were lysed in Pierce RIPA buffer (Thermo Scientific) that included a $1 \%$ protease inhibitor cocktail (Thermo Scientific). After homogenization, the cell lysates were incubated on ice for $30 \mathrm{~min}$ and centrifuged at 15,000 rpm for $15 \mathrm{~min}$ to separate the supernatant from cellular debris. The amount of total protein was estimated using the Qubit Protein assay kit (Thermo Scientific), and the proteins were then mixed with SDS sample buffer and incubated at room temperature for $5 \mathrm{~min}$ after boiling at $100^{\circ} \mathrm{C}$ for $5 \mathrm{~min}$. After electrophoresis on $10 \%$ Mini-Protean ${ }^{\circledR}$ TGX gels (Bio Rad, Hercules, CA, USA), the proteins were transferred onto Trans-Blot ${ }^{\circledR}$ Turbo $0.2 \mu \mathrm{m}$ PVDF membranes (Bio-Rad). The membranes were blocked using the iBind solution kit (Thermo Scientific) and incubated with rabbit anti-KIF11 antibody (catalog no. HPA010568; Sigma-Aldrich, St. Louis, MO, USA) or rabbit anti-actin antibody (catalog no. 4970, 13E5; Cell Signaling Technology, Danvers, MA, USA). Membranes were incubated with anti-rabbit horseradish peroxidase (HRP)-conjugated secondary antibody (GE Healthcare, Buckinghamshire, UK) for $60 \mathrm{~min}$ at room temperature. Protein bands were visualized using Image Quant LAS 4000 mini (GE Healthcare).

Immunocytochemical analysis. Cultured cells were plated onto Lab-Tek II chamber slides (Nalge Nunc International, Rochester, NY, USA). The cells were washed twice with phosphate-buffered saline (PBS) (-), fixed with $4 \%$ paraformaldehyde for $10 \mathrm{~min}$ at room temperature, and permeabilized with $0.1 \%$ Triton X-100 in PBS (-) for 3 min at room temperature. Non-specific binding was blocked with CAS-Block (Invitrogen, Carlsbad, CA, USA) for $7 \mathrm{~min}$ at room temperature before the primary antibody reaction. Then, cells were incubated with rabbit anti-KIF11 antibody (catalog no. HPA010568; Sigma-Aldrich) in PBS (-) containing $1 \%$ bovine serum albumin (BSA) for $60 \mathrm{~min}$ at room temperature in a wet box. After washing with PBS (-), the cells were stained with Alexa 488-conjugated anti-rabbit secondary antibody (Life Technologies, Grand Island, NY, USA) for $60 \mathrm{~min}$ at room temperature in a wet box to protect from light. After washing again with PBS (-), the cells were mounted using Vectashields mounting medium containing DAPI (Vector Laboratories, Inc. Burlingame, CA, USA) and were visualized using BZ-X710 (Keyence, Osaka, Japan).

Immunohistochemistry and tissue microarray. Tumor tissue microarrays were constructed with 99 formalin-fixed, paraffin-embedded primary oral cancer samples, each of which had been obtained as mentioned above. The tissue area for sampling was selected on the basis of visual alignment with the corresponding hematoxylin and eosin (H\&E)-stained section on a slide. For construction of the microarrays, 3, 4, or 5 tissue cores (diameter, $0.6 \mathrm{~mm}$; height, 3-4 mm) taken from a donor tumor block were placed into a recipient paraffin block with a tissue microarrayer (Beecher Instruments, Silver Spring, MD, USA). A core of normal oral epithelial tissue was punched in each case, and $5 \mu \mathrm{m}$ sections of the resulting microarray block were used for immunohistochemical analysis.

To investigate the clinicopathological significance of KIF11 expression in oral cancers, we stained tissue sections using rabbit anti-KIF11 antibody (catalog no. HPA010568; Sigma-Aldrich) and Envision + Kit/HRP (Dako Cytomation 
Table I. The human oral cancer cell lines and oral mucosa keratinocyte.

\begin{tabular}{lll}
\hline Cell line & \multicolumn{1}{c}{ Histology } & Resource distributor $^{\circ}$ \\
\hline FaDu & $\begin{array}{l}\text { Squamous cell carcinoma } \\
\text { of pharynx }\end{array}$ & ATCC $^{\mathrm{a}}$ \\
SCC9 & $\begin{array}{l}\text { Squamous cell carcinoma } \\
\text { of tongue }\end{array}$ & ATCC $^{\mathrm{a}}$ \\
CAL 27 & $\begin{array}{l}\text { Squamous cell carcinoma } \\
\text { of tongue }\end{array}$ & ATCC $^{\mathrm{a}}$ \\
HSC3 & $\begin{array}{l}\text { Squamous cell carcinoma } \\
\text { of tongue }\end{array}$ & RIKEN BRC $^{\text {b }}$ \\
HSC4 & $\begin{array}{l}\text { Squamous cell carcinoma } \\
\text { of tongue }\end{array}$ & RIKEN BRC $^{\text {b }}$ \\
HOMK & $\begin{array}{l}\text { Human oral mucosa } \\
\text { keratinocyte }\end{array}$ & $\begin{array}{l}\text { Cell Research Corp. } \\
\text { Pte Ltd. }\end{array}$ \\
\hline
\end{tabular}

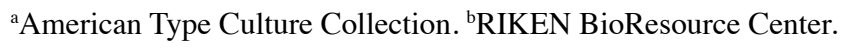

Carpenteria, CA, USA). Tissue microarray slides were deparaffinized, and heat-induced antigen retrieval was accomplished in Target Retrieval Solution ( $\mathrm{pH}$ 9.0) with a Pascal pressurized heating chamber (Dako Cytomation). Anti-KIF11 antibody was added after endogenous peroxidase blocking (Dako Cytomation) and protein blocking. Each section was incubated with HRP-labeled anti-rabbit IgG as the secondary antibody for $30 \mathrm{~min}$. Substrate-chromogen was added, and the specimens were counterstained with H\&E. Three independent investigators without prior knowledge of clinicopathological information semiquantitatively assessed KIF11 positivity. The intensity of KIF11 staining was evaluated using the following criteria: strongly positive (scored as $2+$ ), brown staining in $>70 \%$ of tumor cells completely obscuring cytoplasm; weakly positive (scored as $1+$ ), brown staining in $10-70 \%$ of tumor cells; and absent (scored as 0), brown staining in $<10 \%$ of tumor cells. Cases were considered as strongly positive only if two or more investigators independently identified them as strongly positive.

RNA interference assay. To evaluate the biological functions of KIF11 in oral cancer cells, we used small-interfering RNA (siRNA) duplexes (Sigma-Aldrich). The sequences targeting each gene were as follows: si-KIF11-\#1, 5'-CAGAUUGAUG UUUACCGAATT-3'; si-KIF11-\#2,5'-GAAACUUACUGAUA AUGGUTT-3'; si-EGFP, 5'-GAAGCAGCACGACUUCUU CTT-3'; si-LUC, 5'-CGUACGCGGAAUACUUCGATT-3'. The oral cancer cell lines HSC4 and FaDu were transfected with either of the siRNAs using Lipofectamine 2000 reagent (Invitrogen) according to the manufacturer's instructions. Cell numbers and cell viability were measured using the colony formation assay with Giemsa staining and MTT assay with cell counting kit-8 solution (Dojindo Laboratories, Kumamoto, Japan) at 7 days after transfection. These cells were also used for a caspase-3/7 assay (Image-iT ${ }^{\mathrm{TM}}$ LIVE Green Caspase-3 and -7 Detection kit, Thermo Fisher Scientific) at 3 days after transfection.

KIF11 inhibitor assay. To evaluate the essential role of the kinesin motor ATPase activity of KIF11 in oral cancer cells, we treated HSC4 cells with $0,0.1,1.0$ or $10 \mathrm{nM}$ of a small compound inhibitor against KIF11 (SB743921; Medkoo Biosciences, Chapel Hill, NC, USA), which blocks the ATPase activity of KIF11. These cells were used for MTT assay, flow cytometry, and live-cell imaging.

Flow cytometric analysis. Flow cytometric analysis was performed using the Cycletest Plus DNA reagent kit and the FACS Verse system (BD Bioscience, San Jose, CA, USA). In this analysis, $72 \mathrm{~h}$ after siRNA transfection into HSC4 and FaDu cells or $48 \mathrm{~h}$ after treatment of HSC4 cells with SB743921, 1.0×10 6 oral cancer cells were collected for staining DNA ploidy. The sample was filtered through a $50-\mu \mathrm{m}$ nylon mesh, and it was stored in the dark on ice and kept ready for analyzing the cell cycle within $3 \mathrm{~h}$ using a flow cytometer (BD FACS Verse). Additionally, 20,000 ungated cells were analyzed for DNA content. Evaluation of apoptosis was performed using the Annexin V assay at $72 \mathrm{~h}$ after transfection of siRNAs into HSC4 and FaDu cells.

Live-cell imaging. Live-cell imaging was performed using the Evos FL Auto cell imaging system (Life Technologies) to monitor cytokinetics after transfection of siRNAs for KIF11 or SB743921 treatment. HSC4 cells were seeded into $35 \mathrm{~mm}$ glass dishes in RPMI containing 10\% FBS. Forty-eight hours after transfection of siRNAs for KIF11 or control siRNA into cells, or immediately after treatment of cells with SB743921 or control PBS (-), live-cell imaging was started and images were captured every 20 or $30 \mathrm{~min}$ for $24 \mathrm{~h}$.

Statistical analysis. We examined the correlation of KIF11 protein expression levels determined in tissue microarray analysis with relevant variables, such as patient sex, patient age, primary tumor region, pT factor (pathologic tumor classification), and $\mathrm{pN}$ factor (pathologic lymph node classification). Tumor-specific survival curves were constructed from the date of surgery to the time of death related to oral cancer or to the last follow-up observation. Kaplan-Meier curves were constructed for each relevant variable and for KIF11 expression. Differences in survival times among patient subgroups were analyzed using the log-rank test. Univariate and multivariate analyses were performed with Cox proportional hazards models to determine the prognostic factors in patients with oral cancer. We first analyzed associations between death and possible prognostic factors, including strong KIF11 expression, age, sex, primary region, $\mathrm{pT}$ factor, and $\mathrm{pN}$ factor. Then, a multivariate Cox analysis was applied in stepwise procedures that always forced strong KIF11 expression into the model. All statistical analyses were performed using the StatView statistical program (SAS, Cary, NC, USA).

\section{Results}

KIF11 expression in oral cancer cell lines and tissues. On real-time PCR, we noted high expression of KIF11 in all five 
Table II. Association of KIF11 protein expression in oral cancer tissues with patients' characteristics.

\begin{tabular}{|c|c|c|c|c|c|}
\hline Parameters & $\begin{array}{l}\text { Total } \\
\mathrm{n}=99\end{array}$ & $\begin{array}{c}\text { Strong KIF11 } \\
\text { expression, } n=38\end{array}$ & $\begin{array}{c}\text { Weak KIF11 } \\
\text { expression, } n=26\end{array}$ & $\begin{array}{c}\text { Absent KIF11 } \\
\text { expression, } n=35\end{array}$ & $\begin{array}{c}\text { P-value strong } \\
\text { vs. weak/absent }\end{array}$ \\
\hline \multicolumn{6}{|l|}{ Sex } \\
\hline Male & 56 & 16 & 9 & 18 & $>0.9999$ \\
\hline Female & 43 & 22 & 17 & 17 & \\
\hline \multicolumn{6}{|l|}{ Age (years) } \\
\hline$<65$ & 42 & 14 & 12 & 16 & 0.2975 \\
\hline$\geq 65$ & 57 & 24 & 14 & 19 & \\
\hline \multicolumn{6}{|l|}{ Region } \\
\hline Tongue & 52 & 22 & 18 & 12 & $0.5397^{\mathrm{b}}$ \\
\hline Gingiva & 17 & 8 & 2 & 7 & \\
\hline Buccal mucosa & 7 & 3 & 2 & 2 & \\
\hline Others & 23 & 5 & 4 & 14 & \\
\hline \multicolumn{6}{|l|}{$\mathrm{pT}$ factor } \\
\hline $\mathrm{T} 1-2$ & 78 & 27 & 20 & 31 & 0.6155 \\
\hline T3-4 & 21 & 9 & 4 & 8 & \\
\hline \multicolumn{6}{|l|}{$\mathrm{pN}$ factor } \\
\hline No & 89 & 31 & 24 & 34 & $0.0371^{\mathrm{a}}$ \\
\hline N1-2 & 10 & 7 & 2 & 1 & \\
\hline
\end{tabular}

${ }^{\mathrm{a}} \mathrm{P}<0.05$ (Fisher's exact test); ${ }^{\mathrm{b}}$ Tongue vs gingiva, buccal mucosa and others.

oral cancer cell lines but scarce expression in normal oral epithelial cells (HOMK) (Fig. 1A). In addition, real-time PCR identified higher KIF11 expression levels in 6 of 8 oral cancer tissues than in normal oral epithelia (Fig. 1B). Western blot analysis detected high levels of KIF11 protein expression in all five oral cancer cell lines but hardly detected KIF11 protein expression in normal epithelial cells (Fig. 1C). Furthermore, immunocytochemical analysis identified the KIF11 protein in the cytoplasm of cancer cells that expressed KIF11 (Fig. 1D).

Association of KIF11 expression with poor prognosis in oral cancer patients. Immunohistochemical analysis using tissue microarrays of 99 cases of oral cancers that underwent radical operation demonstrated that KIF11 staining was mainly observed in the cytoplasm of cancer cells. KIF11 was expressed in 64 of the 99 (64.6\%) oral cancer cases (Fig. 2A). Strong, weak, and absent expressions were observed in 38 (38.4\%), $26(26.3 \%)$, and $35(35.3 \%)$ of the 99 cases, respectively. In contrast, positive staining was not observed in adjacent normal tongue epithelial tissues. In the assessment of the association between KIF11 expression and clinical parameters, a significant correlation was noted between strong KIF11 positivity and $\mathrm{pN}$ factor (higher in N1-2, P=0.0371 by Fisher's test; Table II). Furthermore, strong KIF11 expression was significantly correlated with shorter patient survival compared to survival with weak or absent KIF11 expression $(\mathrm{P}=0.0344$, by log-rank test; Fig. 2B). We performed univariate analysis to investigate the correlation of patient prognosis with other clinicopathological factors, including age ( $<65 \mathrm{vs.} \geq 65$ years), sex (female vs. male), tumor location (tongue vs. other locations), pT classification (T1-2 vs. T3-4), pN classification (N0 vs. N1-2), and KIF11 expression status (weak/absent vs. strong). Among those parameters, strong KIF11 expression, advanced pT stage, and advanced $\mathrm{pN}$ stage were significantly associated with poorer prognosis in oral cancer patients $(\mathrm{P}=0.0425,0.0161$ and 0.0021 , respectively, Table III). Multivariate analysis showed that strong KIF11 expression was an independent prognostic factor $(\mathrm{P}=0.0444$, Table III).

Growth inhibition in oral cancer cells by knockdown of KIF11 expression. To confirm whether KIF11 expression could affect the growth of oral cancer cells, siRNAs against KIF11 (siKIF11-\#1 and siKIF11-\#2) and control siRNAs (si-LUC and si-EGFP) were transfected into oral cancer cells (HSC4 and $\mathrm{FaDu}$ ). Western blotting revealed that si-KIF11 decreased KIF11 protein levels in cancer cells compared to the levels in si-controls (Fig. 3A and B). In addition, suppression of KIF11 expression significantly inhibited the cell viability of HSC4 and FaDu cells (Fig. 3C and D). The colony formation assay also showed that knockdown of KIF11 expression decreased the numbers of HSC4 and FaDu cells (Fig. 3E and F).

Induction of apoptosis in oral cancer cells by knockdown of KIF11 expression. To elucidate the effect of KIF11 on cell cycle and cell death, we performed flow cytometric analysis after transfection of si-KIF11 or control siRNAs into HSC4 and FaDu cells. The proportion of cells at subG1 and G2/M phases was significantly higher for cells transfected with 
A

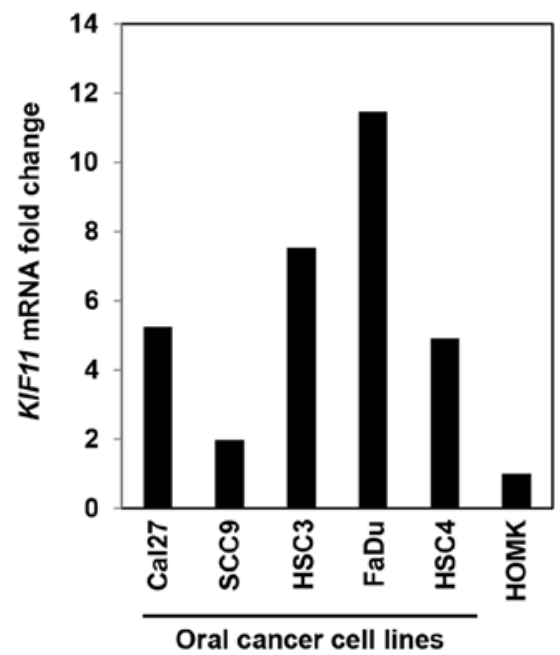

C

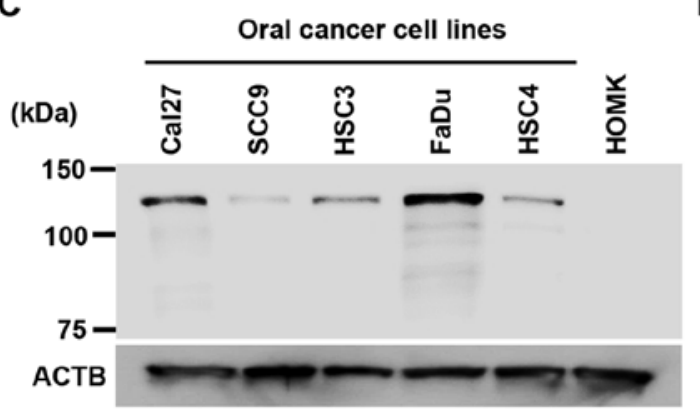

B

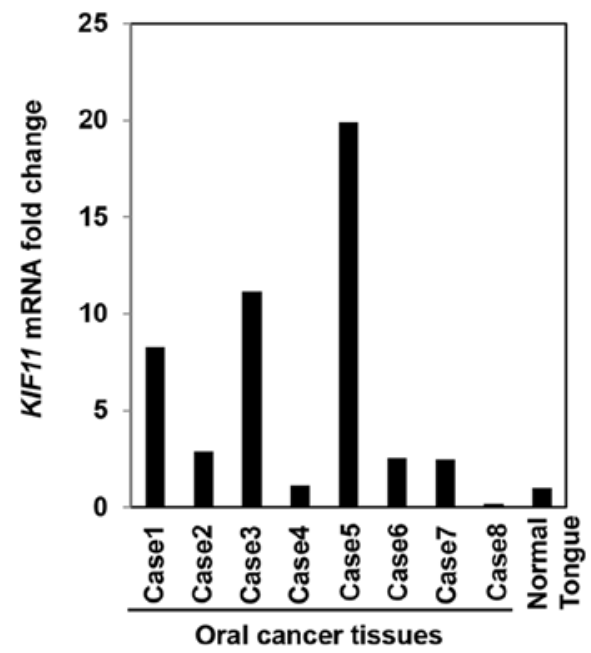

D

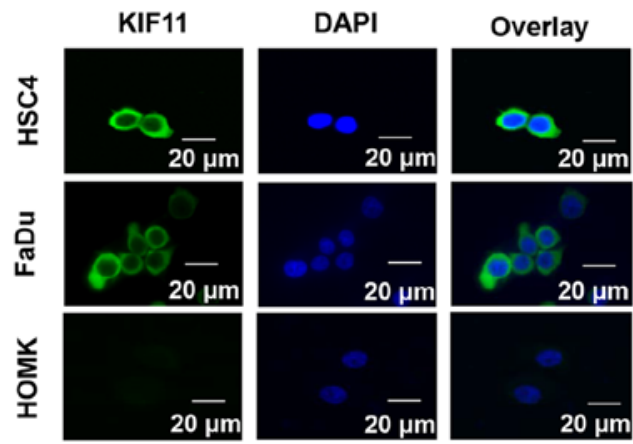

Figure 1. Expression of KIF11 in oral cancer cells and tissues. (A) Expression of KIF11 in oral cancer cell lines. (B) Expression of KIF11 in oral cancer tissues. (C) Expression of KIF11 protein in oral cancer cells. (D) Subcellular localization of endogenous KIF11 protein in HSC4, FaDu and HOMK cells.

A

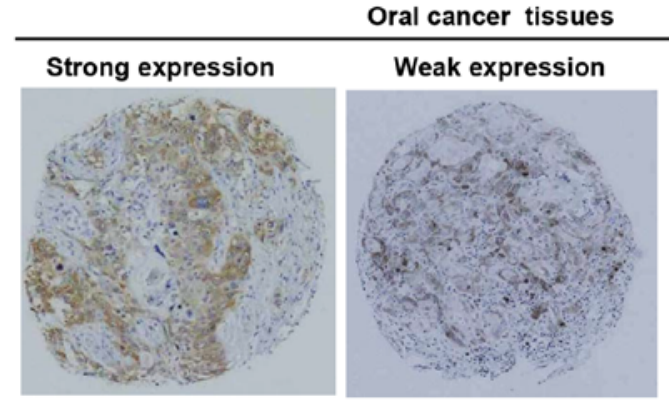

Normal tongue epithelia
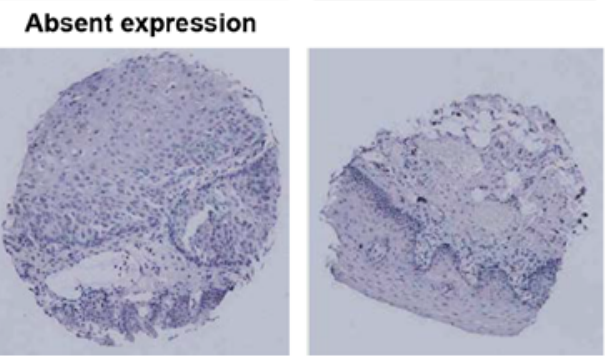

B

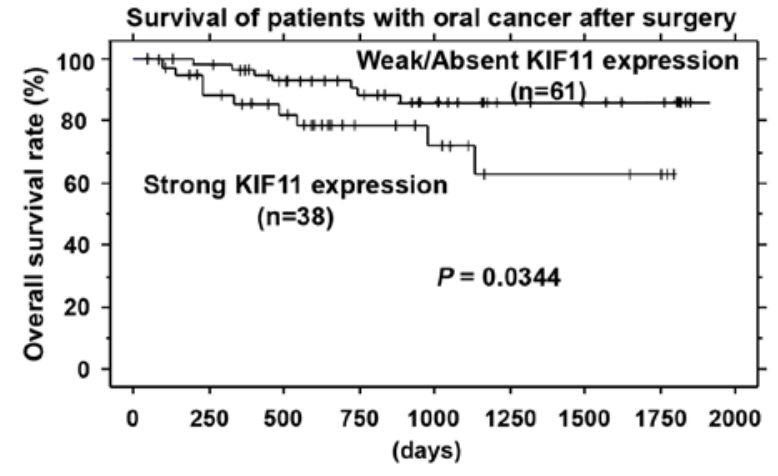

Number at risk 
Table III. Cox's proportional hazards model analysis of prognostic factors in patients with oral cancer.

\begin{tabular}{lclll}
\hline Variables & Hazards ratio & $95 \% \mathrm{CI}$ & Unfavorable/favorable & P-value \\
\hline Univariate analysis & & & & \\
Strong KIF11 expression & 2.798 & $1.035-7.560$ & Strong/weak and absent & $0.0425^{\mathrm{a}}$ \\
Age (years) & 2.803 & $0.901-8.715$ & $\geq 65 /<65$ & 0.0749 \\
Sex & 2.048 & $0.761-5.510$ & Male/female & 0.1557 \\
Region & 1.403 & $0.521-3.777$ & Tongue/others & 0.5026 \\
T-factor & 3.369 & $1.253-9.058$ & T3-4/T1-2 & $0.0161^{\mathrm{a}}$ \\
N-factor & 6.393 & $1.957-20.887$ & N1-2/N0 & $0.0021^{\text {a }}$ \\
Multivariate analysis & & & & $0.0444^{\mathrm{a}}$ \\
Strong KIF11 expression & 2.801 & $1.026-7.648$ & Strong/weak and absent & 0.1699 \\
T-factor & 2.212 & $0.712-6.872$ & T3-4/T1-2 & 0.0528 \\
N-factor & 3.857 & $0.983-15.125$ & N1-2/N0 &
\end{tabular}

${ }^{\mathrm{a}} \mathrm{P}<0.05$; ${ }^{\mathrm{b}}$ Gingiva, buccal mucosa, others.

A

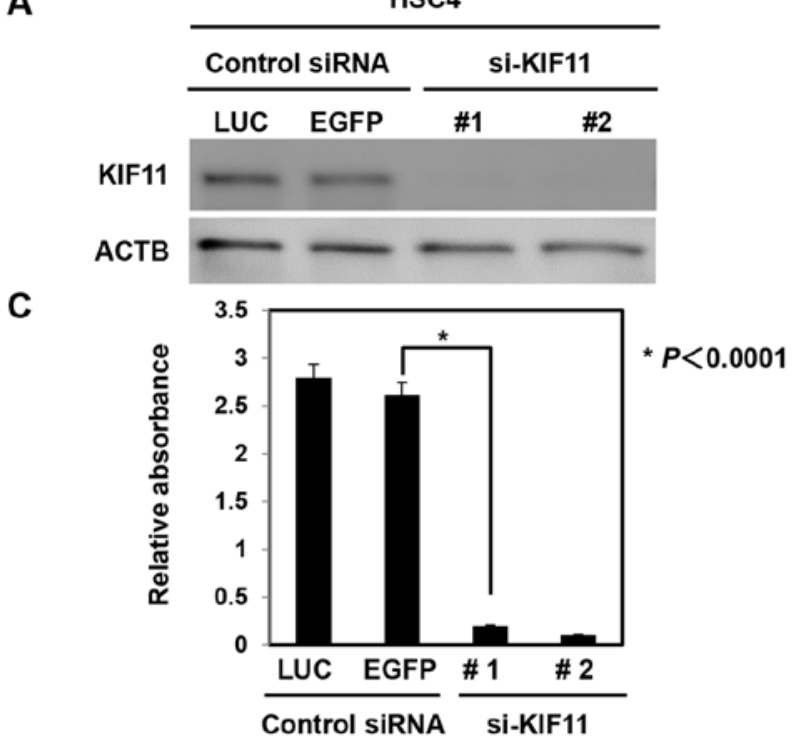

B

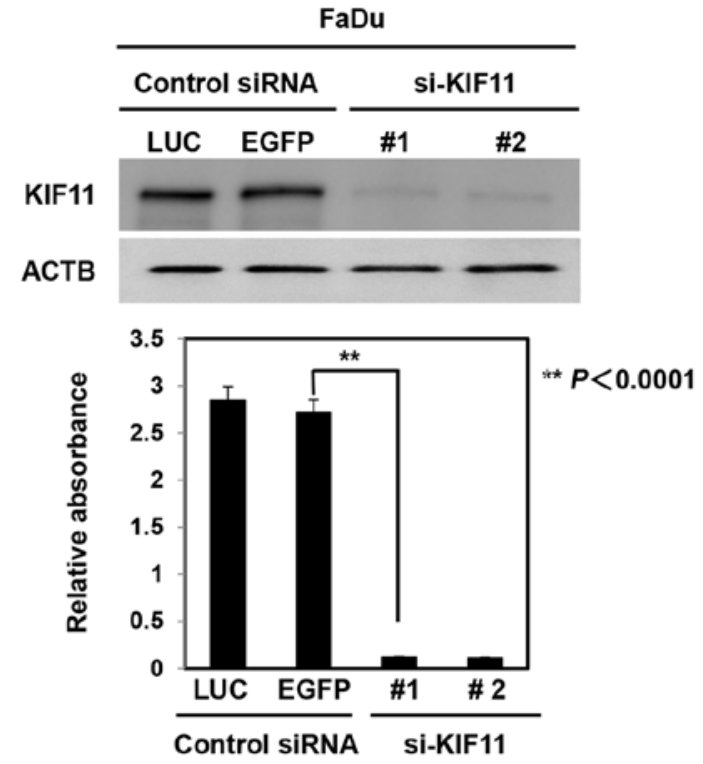

E

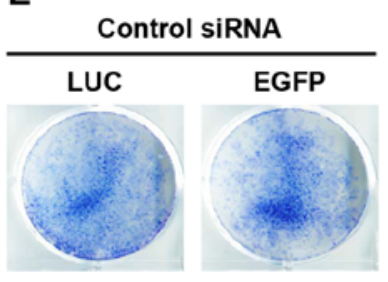

si-KIF11

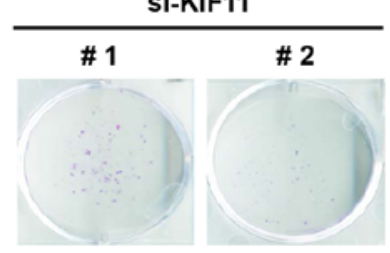

$\mathbf{F}$

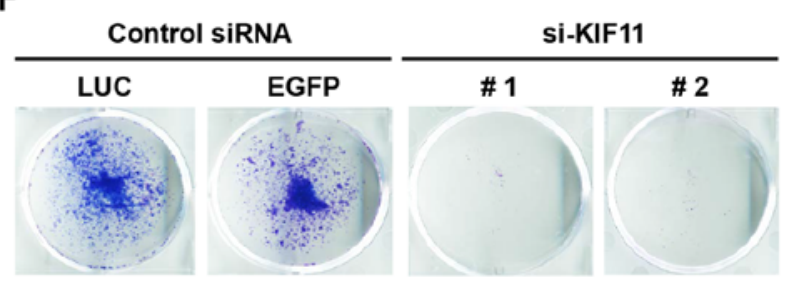

Figure 3. Inhibition of oral cancer cell growth by KIF11 knockdown. (A and B) Expression of KIF11 protein in HSC4 and FaDu cells transfected with siRNAs for KIF11 and control siRNAs. (C and D) MTT assay of HSC4 and FaDu cells transfected with siRNAs for KIF11 and control siRNAs. All assays were performed in triplicate. (E and F) Inhibition of cell growth after transfecting siRNAs using the colony formation assay.

si-KIF11 than for those with control siRNAs (Fig. 4A and B). The Annexin V assay showed that inhibition of KIF11 expression with si-KIF11 significantly increased the occurrence of apoptosis in HSC4 and FaDu cells compared to that in cells with control siRNAs (Fig. 4C and D). The caspase-3/7 assay also detected activation of caspase-3/7 more frequently in HSC4 and FaDu cells transfected with si-KIF11 than in cells with control siRNAs (Fig. 4E and F). We further monitored morphological changes through live-cell imaging of HSC4 cells transfected with siRNAs against KIF11 (Fig. 5). During $24 \mathrm{~h}$ of monitoring with time-lapse imaging, we detected regular cell divisions of HSC4 cells transfected with si-control, while we observed very few cell divisions and subsequent death of HSC4 cells transfected with si-KIF11. 
A

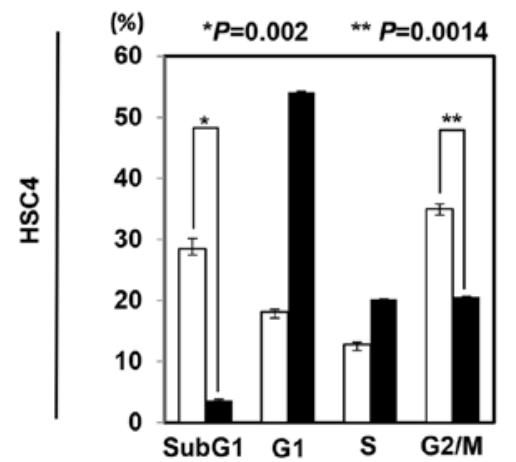

B

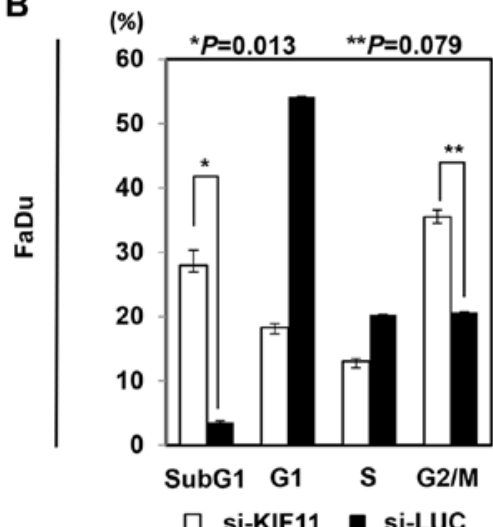

C

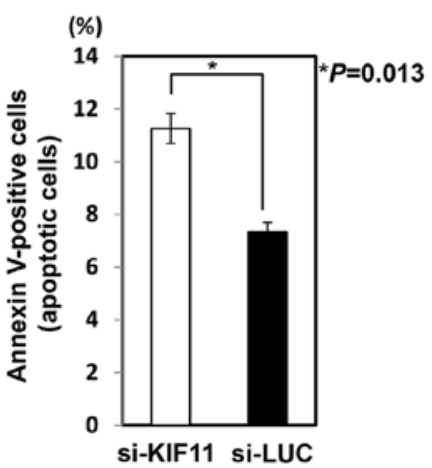

D (\%)

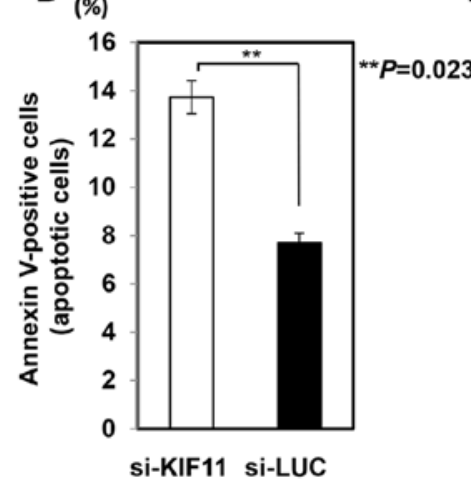

E

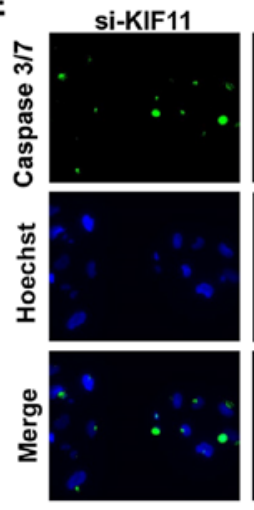

$\mathbf{F}$
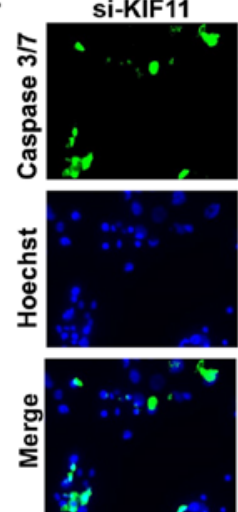

si-LUC

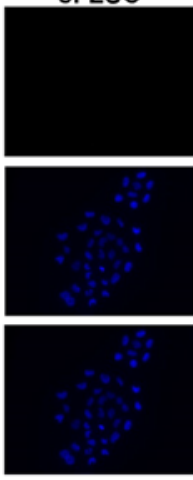

si-LuC

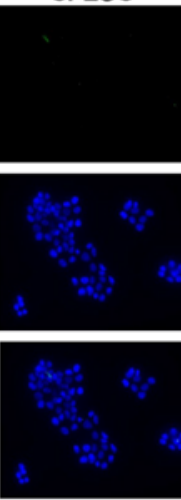

Figure 4. Induction of apoptosis by KIF11 knockdown. (A and B) Population of cells at each phase using flow cytometric analysis of HSC4 and FaDu cells after transfecting siKIF11 or si-control. (C and D) Percentage of apoptotic HSC4 and FaDu cells after transfecting si-KIF11 or si-control. (E and F) Detection of apoptotic cells after transfecting si-KIF11 or si-control (apoptotic cells are stained with green fluorescence).

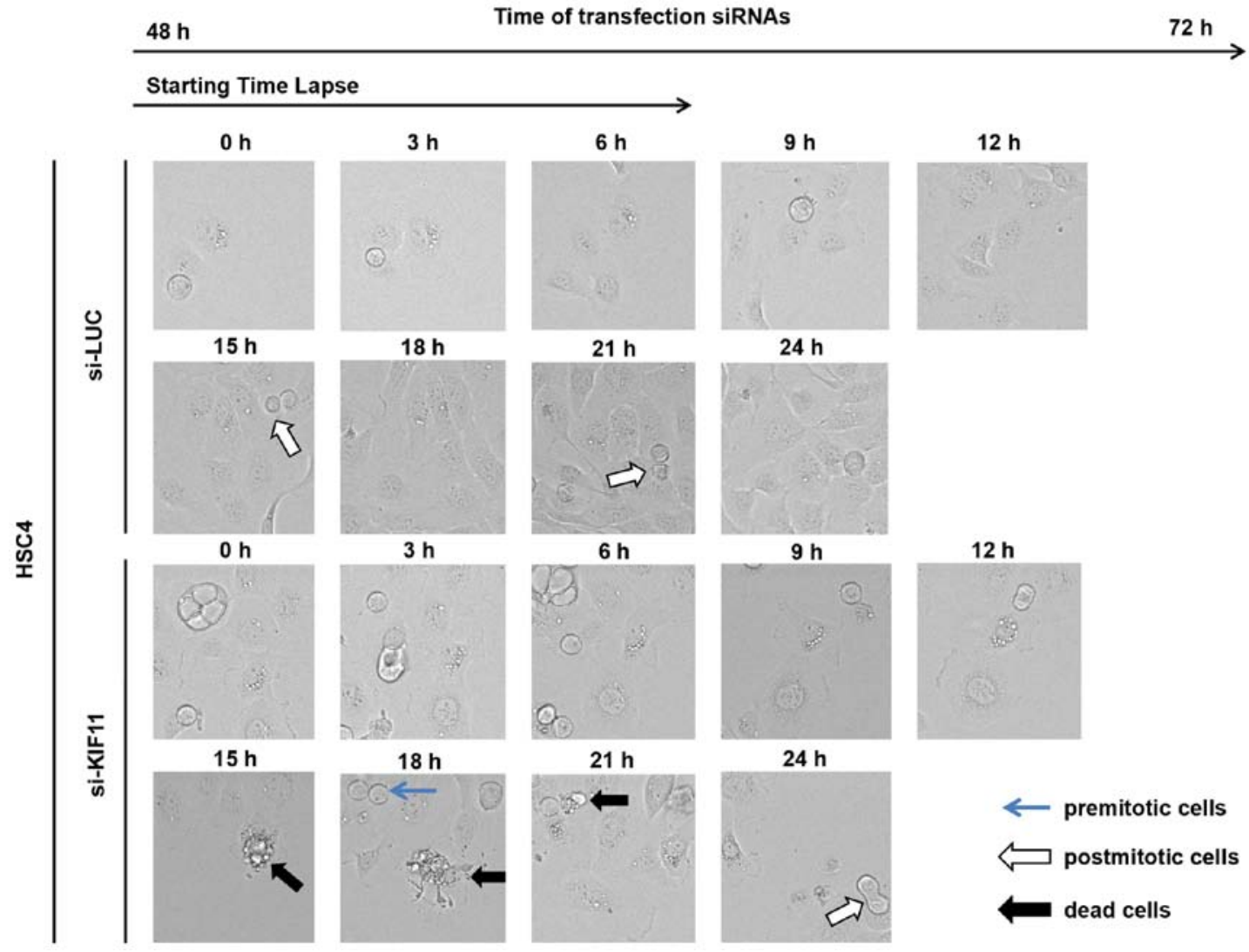

Figure 5. Dysfunction of mitosis after KIF11 knockdown by siRNAs. Detection of postmitotic cells (white arrow), premitotic cells (sky blue arrow), and apoptotic cells (black arrow) by live-cell imaging. 
A

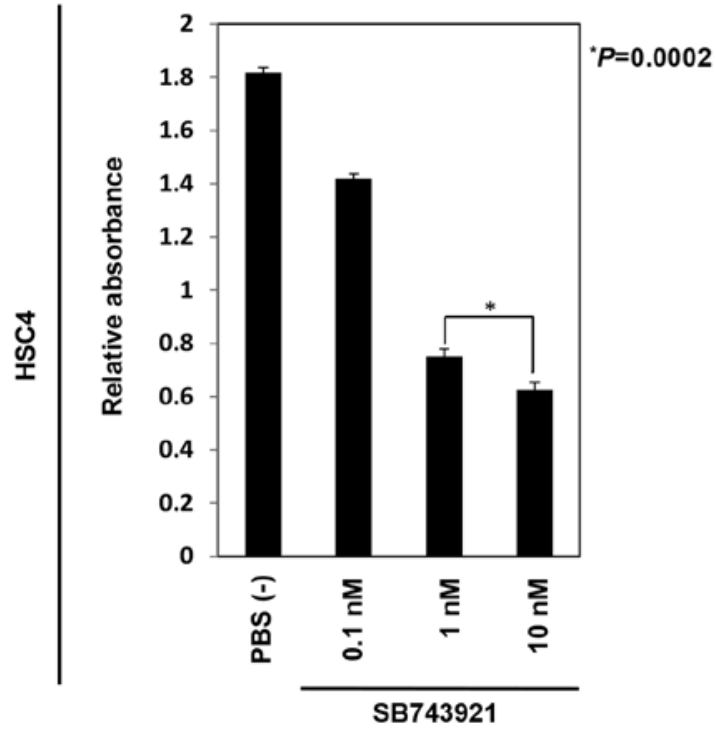

B

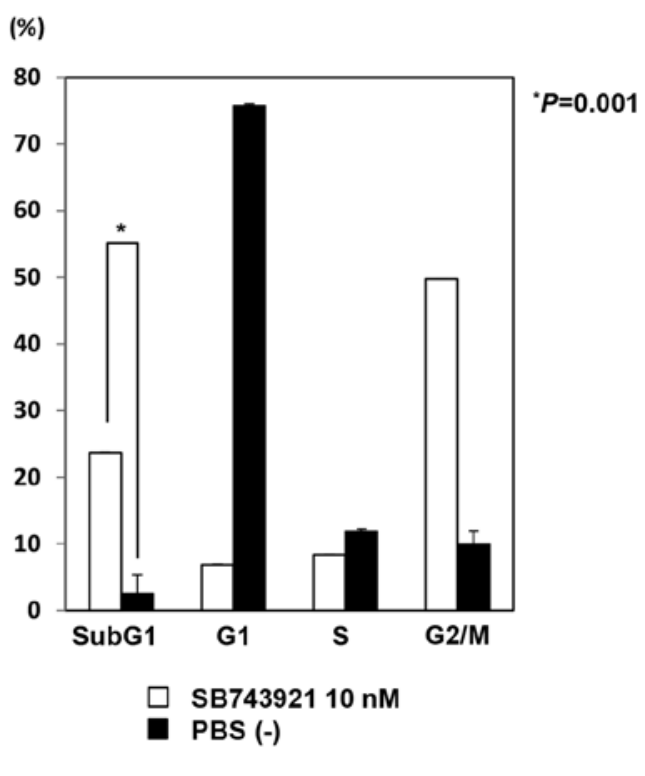

Figure 6. Inhibition of cell growth by SB743921 treatment. (A) MTT assay of HSC4 cells with or without SB743921. (B) Population of cells at each phase using flow cytometric analysis of HSC4 cells with or without SB743921.

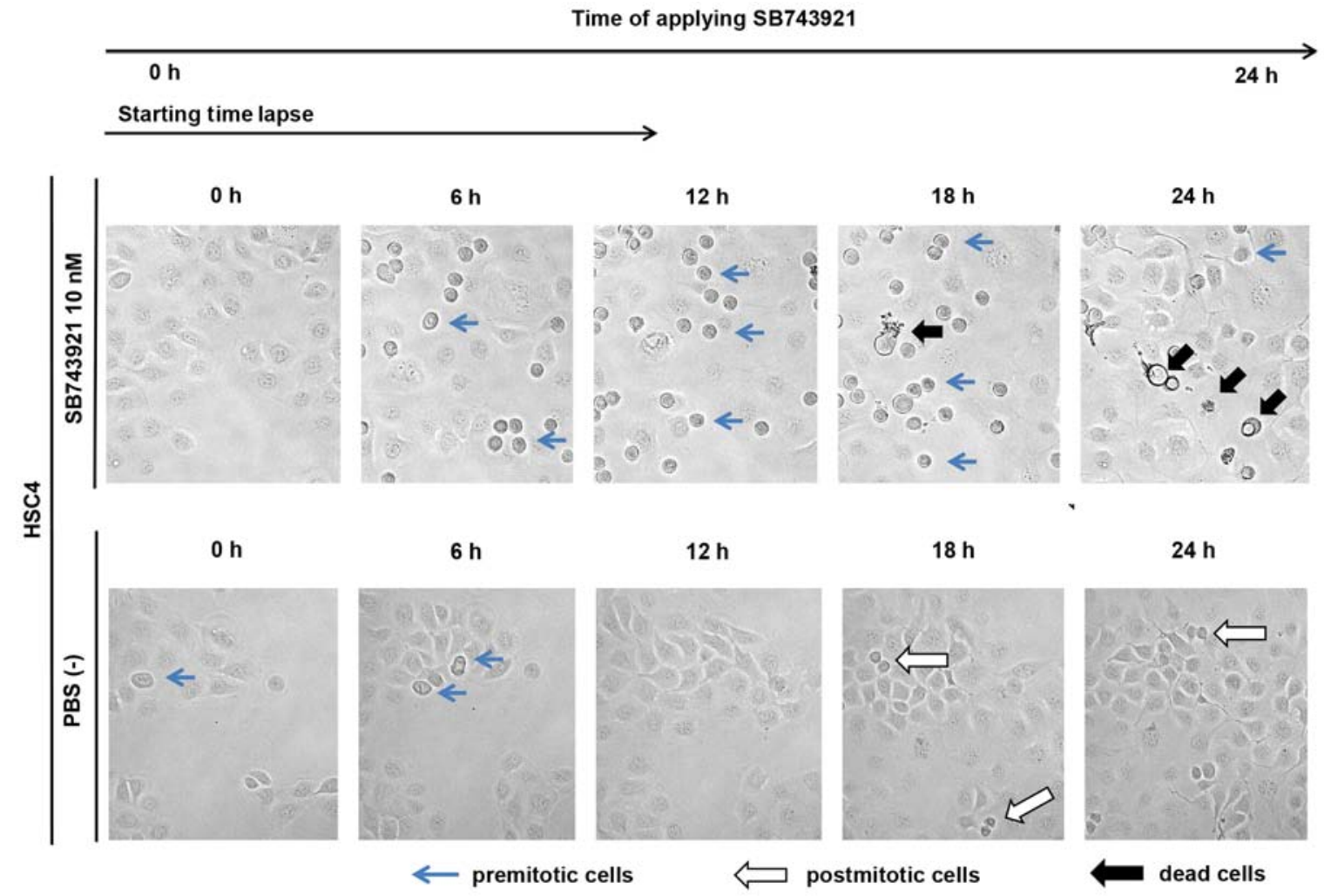

Figure 7. Induction of apoptosis by SB743921 treatment. Detection of postmitotic cells (white arrow), premitotic cells (sky blue arrow), and dead cells (black arrow) by live-cell imaging.

Growth inhibition in oral cancer cells by blocking the kinesin motor ATPase activity of KIF11. To clearly evaluate the functional role of the kinesin motor ATPase activity of KIF11 in oral cancer cells, we incubated HSC4 cells in medium with or without SB743921, which is a small compound that selectively blocks the ATPase activity of KIF11. After $72 \mathrm{~h}$ of incubation with SB743921, MTT assay showed that the viability of HSC 4 cells significantly decreased in a dose-dependent manner (Fig. 6A). Furthermore, flow cytometric analysis performed $48 \mathrm{~h}$ after SB743921 treatment revealed that the population of cells at sub-G1 and G2/M phases was significantly higher than that for cells without SB743921 treatment (Fig. 6B). In live-cell imaging, the control cells without SB743921 treatment showed normal cell division, whereas the 
cells with SB743921 treatment showed cell cycle arrest at the $\mathrm{M}$ phase and subsequent cell death (Fig. 7).

\section{Discussion}

Management of advanced oral cancer involves multiplemodality therapy with surgery, radiation, and chemotherapy. Current understanding of molecular mechanisms and basic signaling pathways in the pathogenesis of oral cancer has led to the development of some new molecular targeted therapies, such as monoclonal antibodies and other molecular targeted agents. Molecular targeted agents are expected to have a high clinical effect against cancer cells, because of their specific anticancer mechanisms of action. To date, the FDA has approved cetuximab, nivolumab, and pembrolizumab as drugs for the treatment of patients with relapsed or advanced head and neck cancers $(39,40)$. Although these drugs have been shown to improve the prognoses of patients with oral cancer, their efficacies and benefits remain limited. Therefore, the identification of new molecular targeted drugs for oral cancer is desired.

In this study, KIF11 was expressed in the majority of oral cancer cells and tissues but was scarcely detected in healthy tongue tissue. In addition, strong KIF11 expression was significantly correlated with poor prognosis in oral cancer patients. Furthermore, the suppression of KIF11 reduced oral cancer cell growth and promoted apoptosis. According to bioGPS (http://biogps.org/\#goto=welcome), KIF11 is not expressed in normal tissues or organs, except early blood cells, such as lymphoblasts and early erythroids. To assess the mechanism of KIF11 activation in oral cancers, we screened for information on genetic aberrations of KIFI1 using a public database involving comparative genome hybridization and genome sequencing. According to cBioportal for Cancer Genomics (http://www.cbioportal.org/), among 915 cases of head and neck squamous cell carcinoma, missense mutations and deletions as well as genetic amplification of KIF11 were detected in only 9 cases $(0.9 \%)$. Thus, we suggest that the overexpression of KIF11 could be caused by epigenetic mechanisms. To our knowledge, our study is the first to report on the functional and clinical relevance of KIF11 in oral cancer.

KIF11 has been reported to play an essential role in centrosome separation by cross-linking microtubules in the mitotic spindle (41). Suppression of KIF11 increased the proportion of cells in the G2/M phase and sub-G1 phase, which suggests that cell death eventually occurred through G2/M arrest and subsequent apoptosis of cancer cells, indicating the important role of KIF11 during G2/M phase transition and cell cycle checkpoints in some cancer cells, such as non-small cell lung cancer (NSCLC) and head and neck squamous cell carcinoma (HNSCC) cells $(42,43)$. In controlling spindle formation during mitosis, KIF11 has been suggested to be phosphorylated through the signal pathways involving various mitotic kinases such as cyclin-dependent kinase 1 (CDK1), NIMA-related kinase 6 (NEK6) and aurora kinase A (AURKA) in some cell lines $(31,32,44,45)$. According to Oncomine database (www.oncomine.org), CDK1, NEK6 and AURKA as well as $K I F 11$ were frequently overexpressed in oral cancer tissues. Therefore functional association between KIF11 protein and these kinases might control cell cycle progression of oral cancer cells. Further detailed studies including novel pathway analyses are warranted to clarify the involvement of KIF11 in oral cancer cell proliferation and survival. On the other hand, histone deacetylase 1 (HDAC1) is colocalized with KIF11 during mitosis and influences the ATPase activity of KIF11 by deacetylating KIF11 (46). KIF11 deacetylation by HDAC1 or other proteins may also promote centromere separation and bipolar spindle formation, leading to metaphase progression and complete cell division in oral cancer cells.

Kinesin inhibitors have been shown to exhibit strong antitumor activity, and many clinical trials on kinesin inhibitors are currently on going $(39,40)$. Recently, small molecules targeting the ATPase activity of KIF11 have been develo ped $(31,32,39,40)$. Accordingly, we focused on SB743921 as a selective KIF11 inhibitor. Our study showed that SB743921 decreased the viability of HSC4 cells through G2/M arrest and subsequent apoptosis. On live-cell imaging, cell waggling and filopodia formation required in the process of polarization in cell mitosis were not observed under SB743921 treatment when compared with the findings in the PBS (-) group. Migrating cells typically form filopodia that extend from the cell surface (47). Previous basic research also showed that SB743921 promotes mitotic arrest and subsequent cell death in certain cancer cell lines (48). In addition, SB743921 caused regression of various types of tumors in human tumor xenograft models in vivo, including colon (Colo205), lung (H69), and breast (MCF7) cancer cell xenografts $(49,50)$. On the other hand, KIF11 inhibitors exhibited powerful anticancer activity in gemcitabine-resistant bladder cancer cells, and it was suggested that SB743921 helps overcome chemotherapy resistance in cancer cells (51). In a previous clinical trial, KIF11 inhibitors helped overcome imatinib resistance in chronic myeloid leukemia cells (52). Targeting KIF11 with small molecule inhibitors, such as SB743921, may be a powerful approach for oral cancer treatment, including metastatic or chemoresistant cancer.

In conclusion, our findings suggest that KIF11 should be considered as a typical oncoprotein in oral cancer. Importantly, KIF11 has a pivotal role in oral cancer growth and survival, and it can be a prognostic factor for oral cancer. Therefore, targeting KIF11 is expected to involve novel treatment strategies, such as immunotherapies and molecular targeted therapies, which could have many powerful biological effects against cancer with minimal side effects in healthy cells.

\section{Acknowledgements}

This study was supported in part by Grant-in-Aid for Scientific Research (B) and Grant-in-Aid for Scientific Research on Innovative Areas from The Japan Society for the Promotion of Science (JSPS KAKENHI grant number JP: 15H04761 and 16H06277). Y.D. is a member of Shiga Cancer Treatment Project supported by Shiga Prefecture (Japan).

\section{References}

1. Siegel R, Ma J, Zou Z and Jemal A: Cancer statistics, 2014. CA Cancer J Clin 64: 9-29, 2014.

2. Dumache R, Rogobete AF, Andreescu N and Puiu M: Genetic and epigenetic biomarkers of molecular alterations in oral carcinogenesis. Clin Lab 61: 1373-1381, 2015. 
3. Manrique OJ, Leland HA, Langevin CJ, Wong A, Carey JN, Ciudad P, Chen HC and Patel KM: Optimizing outcomes following total and subtotal tongue reconstruction: A systematic review of the contemporary literature. J Reconstr Microsurg 33: 103-111, 2017.

4. Bernier J, Domenge C, Ozsahin M, Matuszewska K, Lefèbvre JL, Greiner RH, Giralt J, Maingon P, Rolland F, Bolla M, et al; European Organization for Research and Treatment of Cancer Trial 22931: Postoperative irradiation with or without concomitant chemotherapy for locally advanced head and neck cancer. N Engl J Med 350: 1945-1952, 2004.

5. Cooper JS, Pajak TF, Forastiere AA, Jacobs J, Campbell BH, Saxman SB, Kish JA, Kim HE, Cmelak AJ, Rotman M, et al; Radiation Therapy Oncology Group 9501/Intergroup: Postoperative concurrent radiotherapy and chemotherapy for high-risk squamous-cell carcinoma of the head and neck. N Engl J Med 350: 1937-1944, 2004

6. Winquist E, Oliver T and Gilbert R: Postoperative chemoradiotherapy for advanced squamous cell carcinoma of the head and neck: A systematic review with meta-analysis. Head Neck 29: 38-46, 2007.

7. Chinn SB and Myers JN: Oral cavity carcinoma: Current management, controversies, and future directions. J Clin Oncol 33: 3269-3276, 2015.

8. Daigo Y and Nakamura Y: From cancer genomics to thoracic oncology: Discovery of new biomarkers and therapeutic targets for lung and esophageal carcinoma. Gen Thorac Cardiovasc Surg 56: 43-53, 2008.

9. Daigo Y, Takano A, Teramoto K, Chung S and Nakamura Y: A systematic approach to the development of novel therapeutics for lung cancer using genomic analyses. Clin Pharmacol Ther 94: 218-223, 2013.

10. Ishikawa N, Daigo Y, Takano A, Taniwaki M, Kato T, Hayama S, Murakami H, Takeshima Y, Inai K, Nishimura H, et al: Increases of amphiregulin and transforming growth factor-alpha in serum as predictors of poor response to gefitinib among patients with advanced non-small cell lung cancers. Cancer Res 65: 9176-9184, 2005.

11. Ishikawa N, Daigo Y, Yasui W, Inai K, Nishimura H, Tsuchiya E, Kohno N and Nakamura Y: ADAM8 as a novel serological and histochemical marker for lung cancer. Clin Cancer Res 10 : 8363-8370, 2004.

12. Kakiuchi S, Daigo Y, Ishikawa N, Furukawa C, Tsunoda T, Yano S, Nakagawa K, Tsuruo T, Kohno N, Fukuoka M, et al: Prediction of sensitivity of advanced non-small cell lung cancers to gefitinib (Iressa, ZD1839). Hum Mol Genet 13: 3029-3043, 2004.

13. Kato T, Daigo Y, Hayama S, Ishikawa N, Yamabuki T, Ito T, Miyamoto M, Kondo S and Nakamura Y: A novel human tRNAdihydrouridine synthase involved in pulmonary carcinogenesis. Cancer Res 65: 5638-5646, 2005.

14. Kikuchi T, Daigo Y, Katagiri T, Tsunoda T, Okada K, Kakiuchi S, Zembutsu H, Furukawa Y, Kawamura M, Kobayashi K, et al: Expression profiles of non-small cell lung cancers on cDNA microarrays: Identification of genes for prediction of lymph-node metastasis and sensitivity to anti-cancer drugs. Oncogene 22 2192-2205, 2003.

15. Suzuki C, Daigo Y, Ishikawa N, Kato T, Hayama S, Ito T, Tsuchiya E and Nakamura Y: ANLN plays a critical role in human lung carcinogenesis through the activation of RHOA and by involvement in the phosphoinositide 3-kinase/AKT pathway. Cancer Res 65: 11314-11325, 2005.

16. Kakiuchi S, Daigo Y, Tsunoda T, Yano S, Sone S and Nakamura Y: Genome-wide analysis of organ-preferential metastasis of human small cell lung cancer in mice. Mol Cancer Res 1: 485-499, 2003.

17. Taniwaki M, Daigo Y, Ishikawa N, Takano A, Tsunoda T, Yasui W, Inai K, Kohno N and Nakamura Y: Gene expression profiles of small-cell lung cancers: Molecular signatures of lung cancer. Int J Oncol 29: 567-575, 2006

18. Oshita H, Nishino R, Takano A, Fujitomo T, Aragaki M, Kato T, Akiyama H, Tsuchiya E, Kohno N, Nakamura Y, et al: RASEF is a novel diagnostic biomarker and a therapeutic target for lung cancer. Mol Cancer Res 11: 937-951, 2013.

19. Hayama S, Daigo Y, Yamabuki T, Hirata D, Kato T, Miyamoto M, Ito T, Tsuchiya E, Kondo S and Nakamura Y: Phosphorylation and activation of cell division cycle associated 8 by aurora kinase B plays a significant role in human lung carcinogenesis. Cancer Res 67: 4113-4122, 2007.

20. Ishikawa N, Daigo Y, Takano A, Taniwaki M, Kato T, Tanaka S, Yasui W, Takeshima Y, Inai K, Nishimura H, et al: Characterization of SEZ6L2 cell-surface protein as a novel prognostic marker for lung cancer. Cancer Sci 97: 737-745, 2006.
21. Kato T, Sato N, Hayama S, Yamabuki T, Ito T, Miyamoto M, Kondo S, Nakamura Y and Daigo Y: Activation of Holliday junction recognizing protein involved in the chromosomal stability and immortality of cancer cells. Cancer Res 67: 8544-8553, 2007.

22. Suzuki C, Takahashi K, Hayama S, Ishikawa N, Kato T, Ito T, Tsuchiya E, Nakamura Y and Daigo Y: Identification of Myc-associated protein with JmjC domain as a novel therapeutic target oncogene for lung cancer. Mol Cancer Ther 6: 542-551, 2007.

23. Takahashi K, Furukawa C, Takano A, Ishikawa N, Kato T, Hayama S, Suzuki C, Yasui W, Inai K, Sone S, et al: The neuromedin U-growth hormone secretagogue receptor 1b/neurotensin receptor 1 oncogenic signaling pathway as a therapeutic target for lung cancer. Cancer Res 66: 9408-9419, 2006

24. Taniwaki M, Takano A, Ishikawa N, Yasui W, Inai K, Nishimura H, Tsuchiya E, Kohno N, Nakamura Y and Daigo Y: Activation of KIF4A as a prognostic biomarker and therapeutic target for lung cancer. Clin Cancer Res 13: 6624-6631, 2007.

25. Yamabuki T, Takano A, Hayama S, Ishikawa N, Kato $T$, Miyamoto $\mathrm{M}$, Ito $\mathrm{T}$, Ito $\mathrm{H}$, Miyagi $\mathrm{Y}$, Nakayama $\mathrm{H}$, et al: Dikkopf-1 as a novel serologic and prognostic biomarker for lung and esophageal carcinomas. Cancer Res 67: 2517-2525, 2007.

26. Fujitomo T, Daigo Y, Matsuda K, Ueda K and Nakamura Y: Identification of a nuclear protein, LRRC42, involved in lung carcinogenesis. Int J Oncol 45: 147-156, 2014.

27. Nguyen MH, Koinuma J, Ueda K, Ito T, Tsuchiya E, Nakamura Y and Daigo Y: Phosphorylation and activation of cell division cycle associated 5 by mitogen-activated protein kinase play a crucial role in human lung carcinogenesis. Cancer Res 70: 5337-5347, 2010.

28. Hayama S, Daigo Y, Kato T, Ishikawa N, Yamabuki T, Miyamoto M, Ito T, Tsuchiya E, Kondo S and Nakamura Y: Activation of CDCA1-KNTC2, members of centromere protein complex, involved in pulmonary carcinogenesis. Cancer Res 66 : 10339-10348, 2006.

29. Kobayashi Y, Takano A, Miyagi Y, Tsuchiya E, Sonoda H, Shimizu T, Okabe H, Tani T, Fujiyama Y and Daigo Y: Cell division cycle-associated protein 1 overexpression is essential for the malignant potential of colorectal cancers. Int J Oncol 44: 69-77, 2014

30. Thang PM, Takano A, Yoshitake Y, Shinohara M, Murakami Y and Daigo Y: Cell division cycle associated 1 as a novel prognostic biomarker and therapeutic target for oral cancer. Int J Oncol 49: 1385-1393, 2016

31. Blangy A, Lane HA, d'Hérin P, Harper M, Kress M and Nigg EA: Phosphorylation by $\mathrm{p} 34 \mathrm{cdc} 2$ regulates spindle association of human Eg5, a kinesin-related motor essential for bipolar spindle formation in vivo. Cell 83: 1159-1169, 1995.

32. Rapley J, Nicolàs M, Groen A, Regué L, Bertran MT, Caelles C, Avruch J and Roig J: The NIMA-family kinase Nek6 phosphorylates the kinesin Eg5 at a novel site necessary for mitotic spindle formation. J Cell Sci 121: 3912-3921, 2008.

33. Ferenz NP, Gable A and Wadsworth P: Mitotic functions of kinesin-5. Semin Cell Dev Biol 21: 255-259, 2010.

34. Wakana Y, Villeneuve J, van Galen J, Cruz-Garcia D, Tagaya M and Malhotra V: Kinesin-5/Eg5 is important for transport of CARTS from the trans-Golgi network to the cell surface. J Cell Biol 202: 241-250, 2013.

35. Schneider MA, Christopoulos P, Muley T, Warth A, Klingmueller U, Thomas M, Herth FJ, Dienemann $\mathrm{H}$, Mueller NS, Theis F, et al: AURKA, DLGAP5, TPX2, KIF11 and CKAP5: Five specific mitosis-associated genes correlate with poor prognosis for non-small cell lung cancer patients. Int J Oncol 50: 365-372, 2017.

36. Venere M, Horbinski C, Crish JF, Jin X, Vasanji A, Major J, Burrows AC, Chang C, Prokop J, Wu Q, et al: The mitotic kinesin KIF11 is a driver of invasion, proliferation, and self-renewal in glioblastoma. Sci Transl Med 7: 304ra143, 2015.

37. Kato T, Lee D, Wu L, Patel P, Young AJ, Wada H, Hu HP, Ujiie H, Kaji M, Kano S, et al: Kinesin family members KIF11 and KIF23 as potential therapeutic targets in malignant pleural mesothelioma. Int J Oncol 49: 448-456, 2016.

38. Imai T, Oue N, Nishioka M, Mukai S, Oshima T, Sakamoto N, Sentani K, Matsusaki K, Yoshida K and Yasui W: Overexpression of KIF11 in gastric cancer with intestinal mucin phenotype. Pathobiology 84: 16-24, 2017.

39. Vermorken JB, Mesia R, Rivera F, Remenar E, Kawecki A, Rottey S, Erfan J, Zabolotnyy D, Kienzer HR, Cupissol D, et al: Platinum-based chemotherapy plus cetuximab in head and neck cancer. N Engl J Med 359: 1116-1127, 2008 
40. Ferris RL, Blumenschein G Jr, Fayette J, Guigay J, Colevas AD, Licitra L, Harrington K, Kasper S, Vokes EE, Even C, et al Nivolumab for recurrent squamous-cell carcinoma of the head and neck. N Engl J Med 375: 1856-1867, 2016.

41. Wojcik EJ, Buckley RS, Richard J, Liu L, Huckaba TM and Kim S: Kinesin-5: Cross-bridging mechanism to targeted clinical therapy. Gene 531: 133-149, 2013.

42. Sarli V and Giannis A: Targeting the kinesin spindle protein: Basic principles and clinical implications. Clin Cancer Res 14 7583-7587, 2008.

43. Martens-de Kemp SR, Nagel R, Stigter-van Walsum M van der Meulen IH, van Beusechem VW, Braakhuis BJ and Brakenhoff RH: Functional genetic screens identify genes essential for tumor cell survival in head and neck and lung cancer. Clin Cancer Res 19: 1994-2003, 2013.

44. Bertran MT, Sdelci S, Regué L, Avruch J, Caelles C and Roig J: Nek9 is a Plk1-activated kinase that controls early centrosome separation through Nek6/7 and Eg5. EMBO J 30: 2634-2647, 2011.

45. Ma HT, Erdal S, Huang S and Poon RY: Synergism between inhibitors of Aurora A and KIF11 overcomes KIF15-dependent drug resistance. Mol Oncol 8: 1404-1418, 2014.

46. Nalawansha DA, Gomes ID, Wambua MK and Pflum MKH: HDAC inhibitor-induced mitotic arrest is mediated by eg $5 / \mathrm{kif} 11$ acetylation. Cell Chem Biol 24: 481-492.e5, 2017.

47. Meyen D, Tarbashevich K, Banisch TU, Wittwer C, Reichman-Fried M, Maugis B, Grimaldi C, Messerschmidt EM and Raz E: Dynamic filopodia are required for chemokinedependent intracellular polarization during guided cell migration in vivo. eLife 4: 4, 2015.
48. LoRusso PM, Goncalves PH, Casetta L, Carter JA, Litwiler K, Roseberry D, Rush S, Schreiber J, Simmons HM, Ptaszynski M, et al: First-in-human phase 1 study of filanesib (ARRY-520), a kinesin spindle protein inhibitor, in patients with advanced solid tumors. Invest New Drugs 33: 440-449, 2015.

49. Good JA, Wang F, Rath O, Kaan HY, Talapatra SK, Podgórski D, MacKay SP and Kozielski F: Optimized S-trityl-Lcysteine-based inhibitors of kinesin spindle protein with potent in vivo antitumor activity in lung cancer xenograft models. J Med Chem 56: 1878-1893, 2013.

50. Talapatra SK, Anthony NG, Mackay SP and Kozielski F: Mitotic kinesin Eg5 overcomes inhibition to the phase I/II clinical candidate SB743921 by an allosteric resistance mechanism. J Med Chem 56: 6317-6329, 2013.

51. Sun L, Lu J, Niu Z, Ding K, Bi D, Liu S, Li J, Wu F, Zhang H, Zhao Z, et al: A potent chemotherapeutic strategy with eg5 inhibitor against gemcitabine resistant bladder cancer. PLoS One 10: $\mathrm{e} 0144484,2015$.

52. Yin Y, Sun H, Xu J, Xiao F, Wang H, Yang Y, Ren H, Wu CT, Gao C and Wang L: Kinesin spindle protein inhibitor SB743921 induces mitotic arrest and apoptosis and overcomes imatinib resistance of chronic myeloid leukemia cells. Leuk Lymphoma 56: 1813-1820, 2015

This work is licensed under a Creative Commons Attribution-NonCommercial-NoDerivatives 4.0 International (CC BY-NC-ND 4.0) License. 